\title{
Modernizing Batik Clothes for Community Enterprises Using Creative Design and Colorimetry
}

\author{
Suvita Kaewareelap ${ }^{1}$, Yaowarat Sirisathitkul ${ }^{2}$, Chitnarong Sirisathitkul ${ }^{3 *}$ \\ ${ }^{1}$ School of Languages and General Education, Walailak University, Nakhon Si Thammarat, 80160 Thailand \\ ${ }^{2}$ Shchool of Engineering and Technology, Walailak University, Nakhon Si Thammarat, 80160 Thailand \\ ${ }^{3}$ School of Science, Walailak University, Nakhon Si Thammarat, 80160 Thailand
}

\begin{abstract}
The objective of this study was to modernize batik clothes, a cultural heritage of Southeast Asia, through creative design, color characterization, and collection presentation. Three community enterprises from the southern regions of Thailand participated in designing batik motifs based on their local identities. The pattern of the first manufacturer group was influenced by stones and ancient beads of vivid orange and blue shades. The second community was inspired by the nearby sea, resulting in ocean blue, white, and emerald green colors on batik fabrics. Floras in the south of Thailand dominated the design of the final manufacturer group. Smartphone colorimetry was then used to characterize the batik fabrics. It was demonstrated that this proposed color quantification was not confined to the laboratory, and could easily be carried out by vendors or customers. The collaboration encouraged local batik artisans to use a variety of inspirations, new tools, as well as professional design and production methods. To introduce modernized batik to the public, collections of these newly designed clothes were displayed in a fashion show staged under the theme "Southern Chic." The presentation of Thai batik clothes in seasonal collections highlighted the transformations of local manufacturers and products with increasing appeal to younger people. In addition to conservation and commercial advantages, the modernized approach is accessible and attractive for education purposes, engaging students in cultural heritage.
\end{abstract}

\author{
Keywords: \\ Batik; \\ Community Enterprise; \\ Fashion Design; \\ Smartphone Colorimetry.

$\begin{array}{lrll}\text { Article History: } & & \\ \text { Received: } & 12 & \text { June } & 2021 \\ \text { Revised: } & 14 & \text { September } & 2021 \\ \text { Accepted: } & 06 & \text { October } & 2021 \\ \text { Published: } & 01 & \text { December } & 2021\end{array}$

\section{1- Introduction}

The Fourth Industrial Revolution has strongly impacted business models in the twenty-first century. Industry 4.0 drives society by strengthening and enhancing the competitiveness of companies in various sectors [1]. In line with this trend, Thailand 4.0 has the goal of reforming the country's economic structure into a "value-based economy" by focusing on innovation, technology, high-value services, and creativity [2]. In addition to economic prosperity, the creative industry benefits human empowerment, cultural heritage conservation, and community development. The textile industry is crucial to the creative industry, combining talent and artistic skills with scientific technology to create wealth and employment [3,4].

Batik fabrics are textiles with motifs indigenous to Southeast Asia. They are also traditional arts that belong to the Miao ethnic group in southwest China [5,6]. In the nineteenth century, they were exported from Indonesia and became part of the African culture [7]. While the wax-resist and dye-painting techniques applied in batik production were adopted

\footnotetext{
*CONTACT: schitnar@mail.wu.ac.th
}

DOI: http://dx.doi.org/10.28991/esj-2021-01319

(C) 2021 by the authors. Licensee ESJ, Italy. This is an open access article under the terms and conditions of the Creative Commons Attribution (CC-BY) license (https://creativecommons.org/licenses/by/4.0/). 
to create other products worldwide, batik arts are uniquely crafted with local wisdom recognized as an intangible cultural heritage by the United Nations Educational, Scientific and Cultural Organization (UNESCO). Their motifs and colors reflect the sociocultural aspects of the areas where they are created [7, 8]. It is fascinating that batik patterns from various areas in Indonesia and Malaysia have subtle religious and philosophical meanings [5, 9-11]. Indonesian and Malaysian batik cultures have strong influences in the southern regions of Thailand, where batik clothes are widely manufactured and worn in daily life. Thai products are domestically famous for their colorful appearance and texture, appropriate for tropical climates. However, the Thai batik, which is produced mainly by local communities is facing challenges in the era of globalization. Another goal is to encourage younger generations, who seemingly have little interest in batik, to conserve this cultural heritage.

One strategy to enhance the knowledge of batik is through training and online courses. Mulyanto et al. created a training model to develop the creativity of designers [12]. Widiaty et al. proposed a multiplatform curriculum framework of batik for vocational high school students [13]. Budiyanto et al. suggested that the philosophy and batik-making courses offered by Indonesian universities could be beneficial to learners around the world, create identities of the universities, and increase income for communities [14]. The exhibition of traditional objects on mobile platforms is another way to promote and value cultural heritage [15]. Widiaty et al. employed augmented reality to present information about batik culture [16]. In addition to transferring its knowledge to younger generations to ensure its sustainability, new techniques have been proposed to facilitate batik manufacturing processes. Laitupa et al. demonstrated the computer-based creation of new batik motifs [17], whereas Tian et al. developed automatic batik flower patterns based on fractal geometry [18]. For pattern recognition, neural networks and deep learning have been implemented on batik fabrics [19, 20]. To characterize fabric colors, smartphone colorimetry was demonstrated and compared with the standard CIE L*a*b* color measurement using a HunterLab spectrophotometer [21].

This study aimed to support three community enterprises in southern Thailand by modernizing their batik products. Batik clothes in Southeast Asia are primarily produced by small and medium-sized enterprises (SMEs), but the value of batik exports from Indonesia to foreign countries has increased significantly every year [12]. Because motifs and designs are dominant factors in boosting income from batik products, development should focus on creativity in designing motifs and clothes. However, a problem of creativity not being sufficiently explored in the batik industry has been identified. Even the work of young batik artisans is routinely based on traditional designs and processes [12]. The introduction of new designs and techniques by academic researchers may not be accepted by batik artisans. The transformation of traditional batik clothes into modern outfits also risks losing local identity [7, 12]. To avoid these pitfalls, participatory action research was employed to modernize batik clothes. Their colors were characterized based on smartphones, and a fashion show was organized to present the newly designed batik clothes.

This article is organized into five main sections. After this introduction, the design and creation, color characteristics, and collection presentation are described in the methodology section. The results from each step are then presented, followed by a discussion with references to recent publications. The article concludes with a summary of its contributions and achievements.

\section{2- Research Methodology}

Three community enterprises in southern Thailand participated in the modernization of batik clothes: the Barnrak and Linesen (also known as Islam batik) groups, located in the Nakhon Si Thammarat province, and the Ying batik group, located in the Phuket province. All groups had locally manufactured batik for more than 10 years. Although they can make clothing (dresses, shirts, and pants), their products were primarily sold in the form of raw fabrics. To add value and modernize batik clothes for these community enterprises, participatory action research was implemented. The process is summarized in a flowchart adapted from [12] in Figure 1 and detailed in the following three subsections.

\section{2-1-Fabric Design and Creation}

The researchers, batik artisans, and entrepreneurs collaborated to design new motifs and colors for fabric handwriting and painting. The natural resources and cultural heritage of southern Thailand were used as inspiration. The Barnrak group presented patterns accentuated with colored stones and ancient beads. Instead of the commonly used wax, they employed rice milk to propagate cracks within the dye to generate a unique pattern. The location of the Linesen group was reflected through marine-oriented arts with wave, shell, and coral reef images. These motifs were obtained from tjanting-writing and wax brushing. Finally, the Ying batik group with their specialized handwriting skills filled their fabrics with colors and motifs based on tropical plants including orchid flowers, torch ginger, coconut leaves, rubber leaves, and palm leaves.

To turn the batik fabrics into clothes, a design brief was used to guide the participants toward achieving common goals. Identified participants settled on fashion concepts, styles, moods, and tones, and then the presentation theme was selected. Inspirations from individual experiences and impressions were exchanged and then referenced to fashion concepts via image searching on the Internet. Such reference images and fashion references kept the works aligned with 
current fashion trends to better meet consumer demands. In addition, the contextual, consumer, and competition aspects were considered in the design process. A moodboard was then drawn to visualize the collective ideas and inspirations; 2D fashion design sketches were produced using either a computer or hand drawing for each item of clothing. Finally, the clothes were manufactured based on the designated allocation of fabrics with appropriate textures.

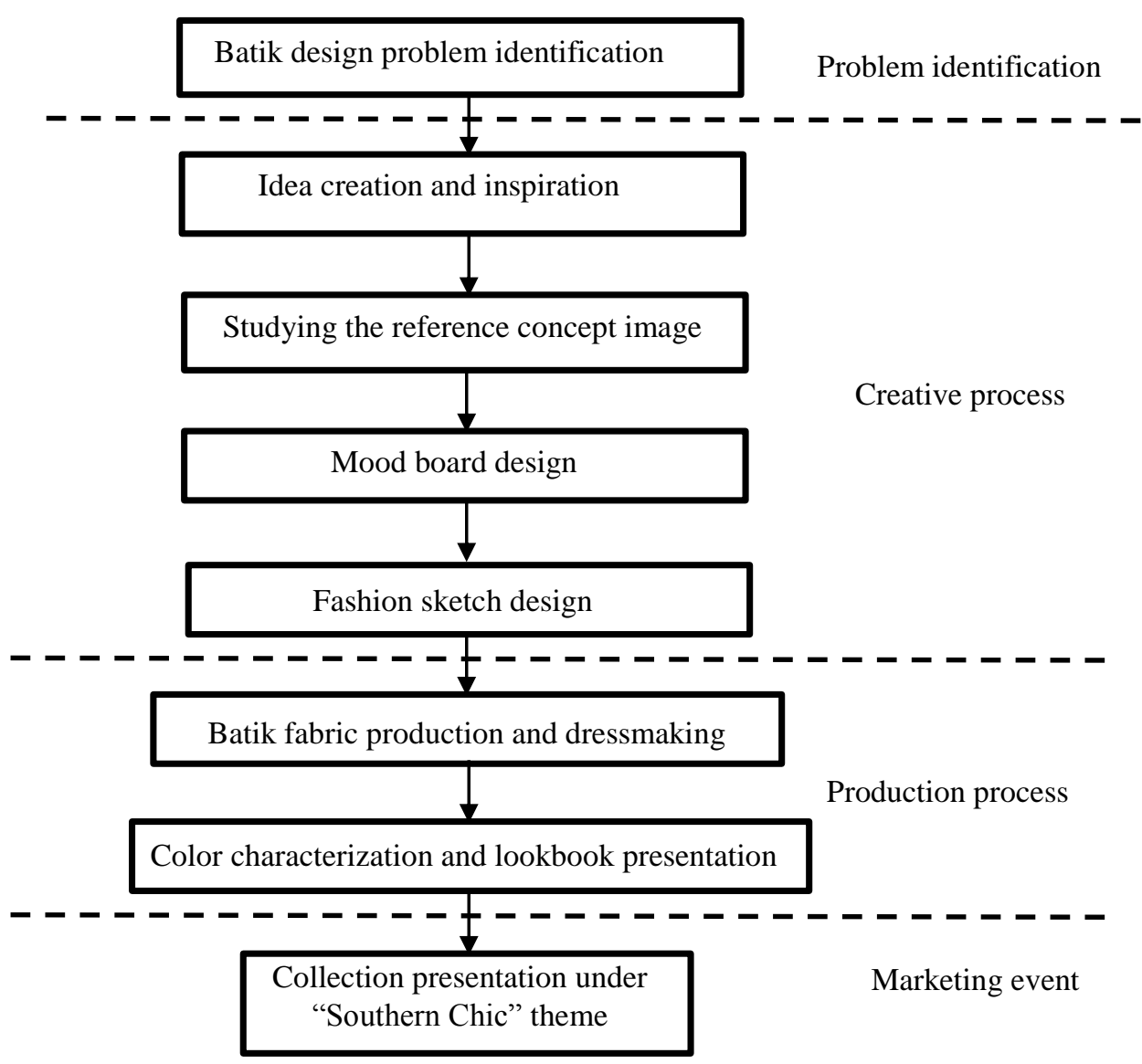

Figure 1. Process flowchart used to modernize batik clothes for community enterprises.

\section{2-2-Color Characterization}

The colors of the batik fabrics were measured by a non-expert using an Android smartphone (Oppo F9) with a colorimetric application called "Colorimeter." The smartphone camera captured images of each fabric at a distance of $10-30 \mathrm{~cm}$. The light reflected from the fabric was collected by the optical parts of the smartphone and converted into electrical signals by complementary metal-oxide-semiconductor (CMOS) image sensors. The colorimetric application analyzed the pixels at the center of the digital images according to the RGB and CIE L*a* $\mathrm{b}^{*}$ color spaces as well as hue and chroma values.

In the RGB color space commonly used by electronic screens, each color results from a primary color combination of red, green, and blue. The CIE L*a*b* color space imitates nonlinear responses of the human eye and, hence, is perceptually uniform to human color vision. The color is represented by $\mathrm{L}^{*}$ from 0 to 100 (darkness to lightness), a* from -128 to +127 (greenness to redness), and $b^{*}$ from -128 to +127 (blueness to yellowness) [21]. Chroma and hue angle are attributes ranging from 0 to 100 and from $0^{\circ}$ to $360^{\circ}$, respectively [21]. The chroma indicates the colorfulness referenced to the brightness of a white object, whereas the hue varies from red to yellow, green, cyan, blue, magenta, and back to red. Finally, the combination of values was matched with the reference in the "Colorimeter" application, and the color name was displayed.

\section{2-3-Collection Presentation}

Three summer collections from the selected community enterprises were presented under the same theme in a fashion show. Each collection comprised male clothes (shirts, overcoats, and pants) and female clothes (dresses, overcoats, and pants) with accessories including bags, bandanas, scarves, earrings, and bracelets. All collections were photographed and displayed in a lookbook. To organize the fashion event, a stage manager and a choreographer were recruited. A coordinator helped the researchers prepare the venue and advertise the event. Seventeen female and four male models were cast from among Walailak University students. Four makeup artists and hairstylists were hired, and the models also needed dressers. 
Table 1. Changes observed in each stage of batik clothes production by three community enterprises.

\begin{tabular}{|c|c|c|c|}
\hline Stage & Factors & Before this work & After this work \\
\hline \multirow{4}{*}{ Design } & Concept & $\begin{array}{l}\text { The concept was based on individual } \\
\text { experiences and routines. }\end{array}$ & $\begin{array}{l}\text { Batik artisans were encouraged to draw a concept based on the } \\
\text { season, fashion trends, and consumer demand. }\end{array}$ \\
\hline & $\begin{array}{l}\text { Inspiration and } \\
\text { reference }\end{array}$ & $\begin{array}{l}\text { Batik artisans were inspired by individual } \\
\text { experiences and the local surroundings, without } \\
\text { reference. }\end{array}$ & $\begin{array}{l}\text { Beside experiences and surroundings, the collaboration } \\
\text { encouraged batik artisans to find inspiration from the Internet. } \\
\text { References were made to successful products. }\end{array}$ \\
\hline & Color & $\begin{array}{l}\text { Batik products only emphasized vivid colors } \\
\text { without any inspection. }\end{array}$ & $\begin{array}{l}\text { Vivid colors remained the highlight but were balanced by lighter } \\
\text { elements. Colors could be quantified by smartphone colorimetry. }\end{array}$ \\
\hline & Design sketch & $\begin{array}{l}\text { Batik artisans followed their routines and } \\
\text { experiences without any design sketches. }\end{array}$ & Design sketches were adopted to guide the production. \\
\hline \multirow{3}{*}{ Production } & Materials & Cotton and muslin fabrics were mostly used. & $\begin{array}{l}\text { More fabric types were considered for suitable texture selection } \\
\text { in each use. }\end{array}$ \\
\hline & $\begin{array}{l}\text { Pattern from } \\
\text { cutting }\end{array}$ & $\begin{array}{l}\text { Motifs were randomly distributed on the } \\
\text { clothes. }\end{array}$ & $\begin{array}{l}\text { The positions of motifs were planned and patterned on the } \\
\text { clothes. }\end{array}$ \\
\hline & Sewing & Sewing was a routine step. & The neatness of the sewing was systematically inspected. \\
\hline \multirow[t]{2}{*}{ Marketing } & Collection & $\begin{array}{c}\text { Products were not made into clothing } \\
\text { collections. They were sold separately or as } \\
\text { raw fabrics. }\end{array}$ & Batik clothes were available as collections for sale. \\
\hline & Consumer & $\begin{array}{l}\text { Batik clothes were primarily purchased by } \\
\text { customers aged over } 40 \text { years. }\end{array}$ & Batik products were also aimed at younger people. \\
\hline
\end{tabular}

\section{3- Results}

\section{3-1-Fabric Design and Creation}

The changes made in this study are summarized in Table 1. Local batik artisans were encouraged to modernize their products based on season, fashion trends, and consumer demand. The participatory process in the design stage incorporated natural resources and the cultural heritage of southern Thailand into batik fabrics. The Barnrak group represented the colors of stones and ancient beads with vivid orange and blue shades. In contrast, the Linesen group conveyed a marine theme through ocean blue, white, and emerald green colors, whereas fabrics from the Ying batik group were predominantly green and brown. The motifs shown in Figure 2 are appropriate for handwritten batik (batik "tulis") but could also be applied in stamped batik (batik "cap") and combination batik.

In addition to individual experiences and local surroundings, the collaboration used the Internet as a source of inspiration, and references were made to successful products. By adopting silk and shinmai fabrics, batik artisans had more options in selecting suitable textures for particular shirts, pants, and dresses. The production was guided by design sketches. In addition to the design, the production steps were compatible with professional processes. The positions of the motifs were planned and patterned on clothes. The neatness of the sewing was examined.

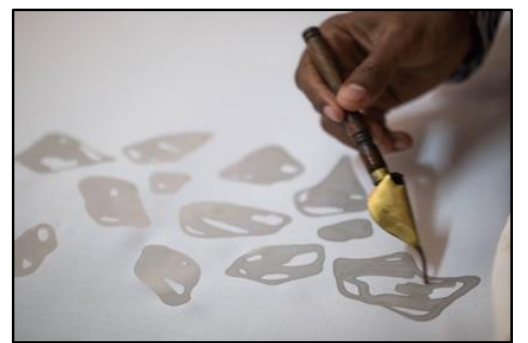

(a)

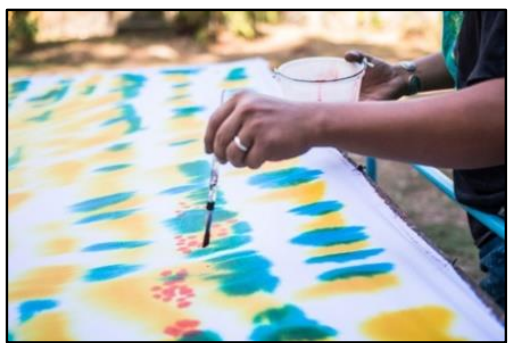

(b)

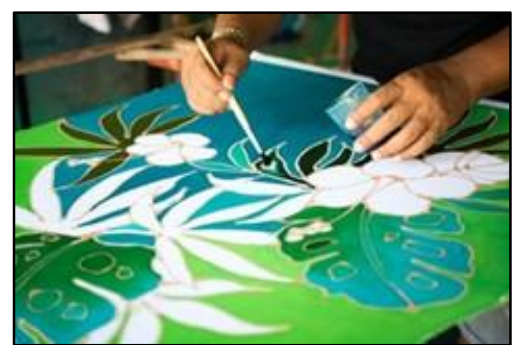

(c)

Figure 2. Hand-writing and fabric painting to create new batik by the (a) Barnrak, (b) Linesen, and (c) Ying batik groups.

\section{3-2-Color Characterization}

The images of the batik fabrics captured for smartphone colorimetry are shown in Figure 3 . The values of the hue angle, chroma, and parameters in the RGB and CIE color spaces are displayed in the top left corner. The orange fabric from the Barnrak group in Figure 3(a) exhibits a high $\mathrm{R}$ value and hue angle of approximately $30^{\circ}$. The large positive values of $a^{*}$ and $b^{*}$ in the CIE color space are consistent with the orange color. The application also matched this measurement with the color name "Peru." All color parameters predictably differ in the fabrics from the Linesen group, as shown in Figure 3(b). The blue color dominates, yielding a high B at the expense of the R value. The $\mathrm{a}^{*}$ and $\mathrm{b}^{*}$ values are both negative, whereas the hue angle increases beyond $180^{\circ}$. The hue angles were further increased to $270^{\circ}$ in the case of purple fabrics from the same group (not shown here). Overall, the products were bright and colorful, as they are famously known for, but the vivid colors were balanced by lighter elements according to the ideas exchanged. 
This demonstration shows that the batik colors can be quantitatively described by smartphone colorimetry without an expensive spectrophotometer or a skilled operator. Owing to the widespread use of smartphones, vendors and customers can conveniently examine batik products. This facile measurement, not confined to the laboratory, works with different smartphones and colorimetric applications. The distance between smartphone is not a sensitive factor. However, the limitation of smartphone colorimetry is its sensitivity to lighting conditions. The color deviation can be minimized by illumination with the same white light source, resulting in accuracy of the measured parameters within the acceptability threshold of color differences [21]. However, the $\mathrm{L}^{*}$ and chroma values are highly susceptible to illuminance, which is dependent on the light source power and distance, when taking the measurement. It follows that these two values are not primarily used for comparison and standardization.

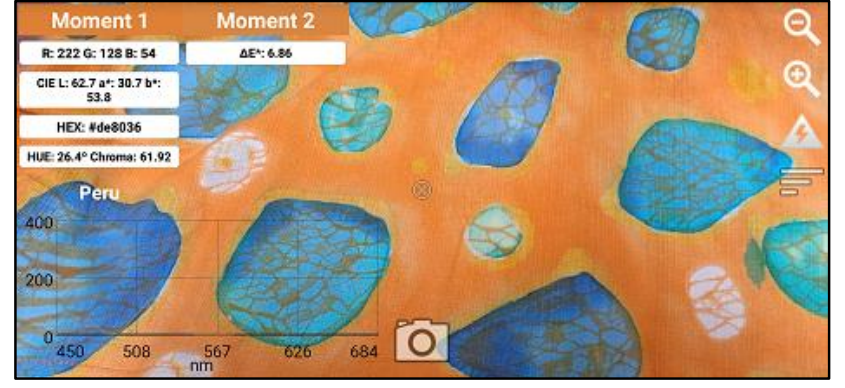

(a)

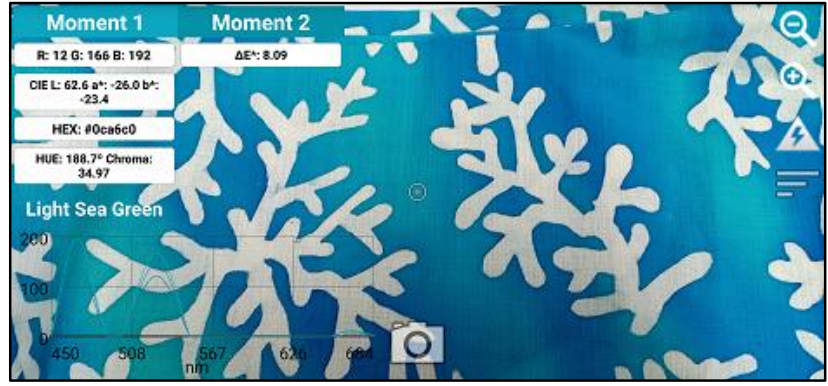

(b)

Figure 3. Smartphone colorimetry on new batik fabrics by the (a) Barnrak, and (b) Linesen groups.

\section{3-3-Collection Presentation}

Figure 4 shows three clothing collections from the Barnrak, Linesen, and Ying batik groups in the lookbook. Each collection was comprised of new seven dresses, retaining the distinctive identity of each community. The geographical aspect of the region was also highlighted. The styles were modernized in a way that enabled the batik artisans, entrepreneurs, and researchers to mutually agree and present them under the theme "Southern Chic." The theme also underlined the transition of the community enterprises from original equipment manufacturers (OEM) to original design manufacturers (ODM).

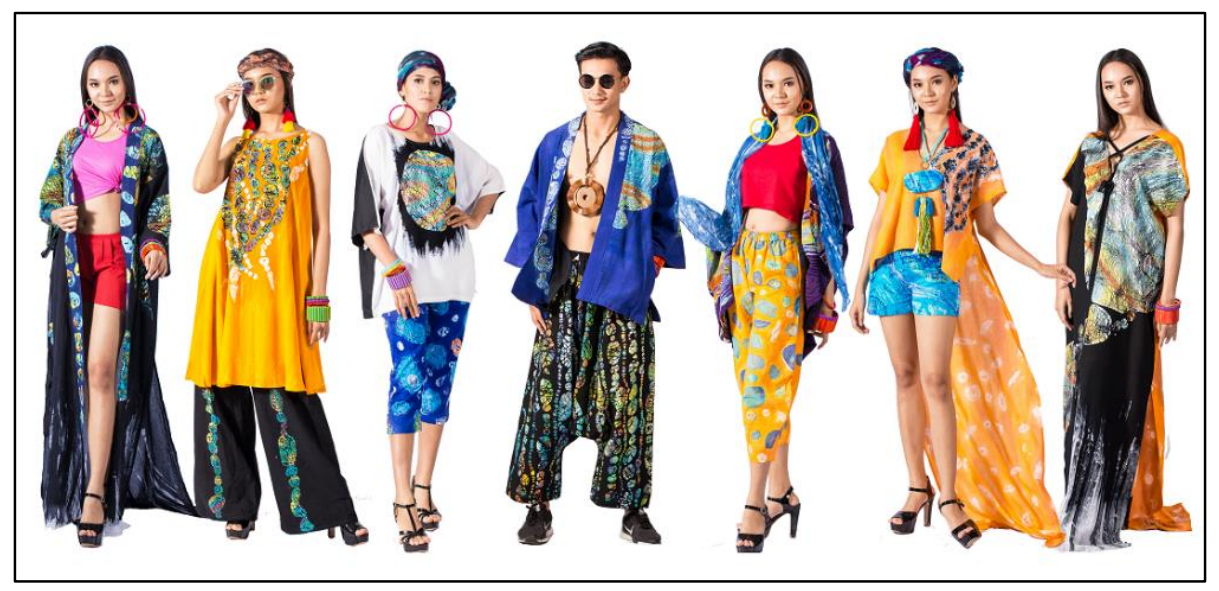

(a)

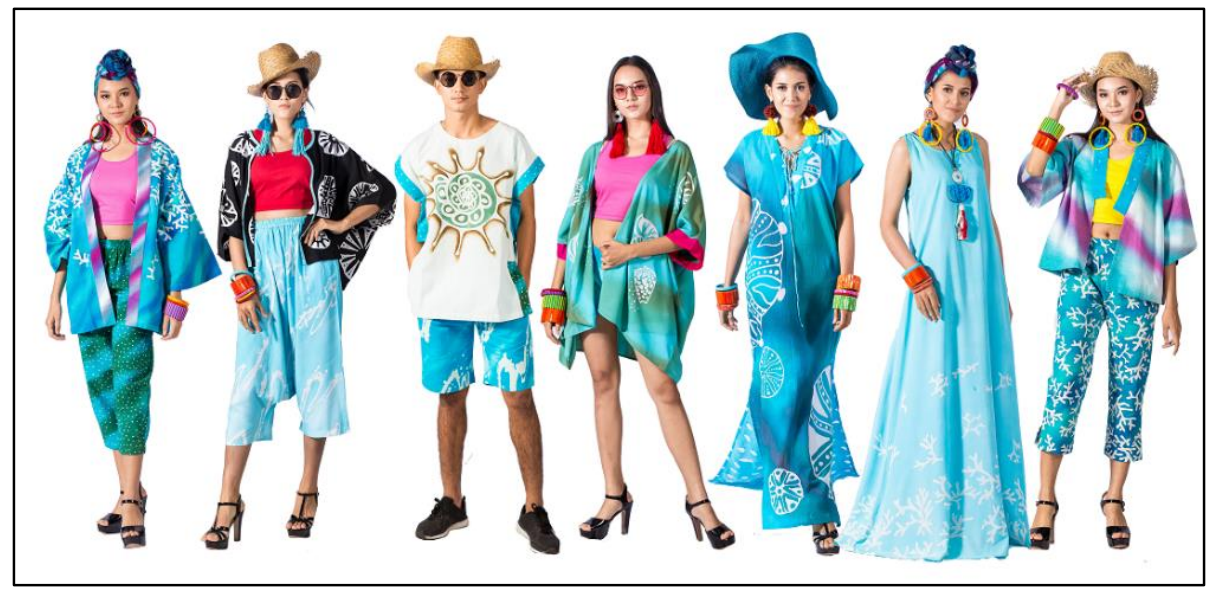

(b) 


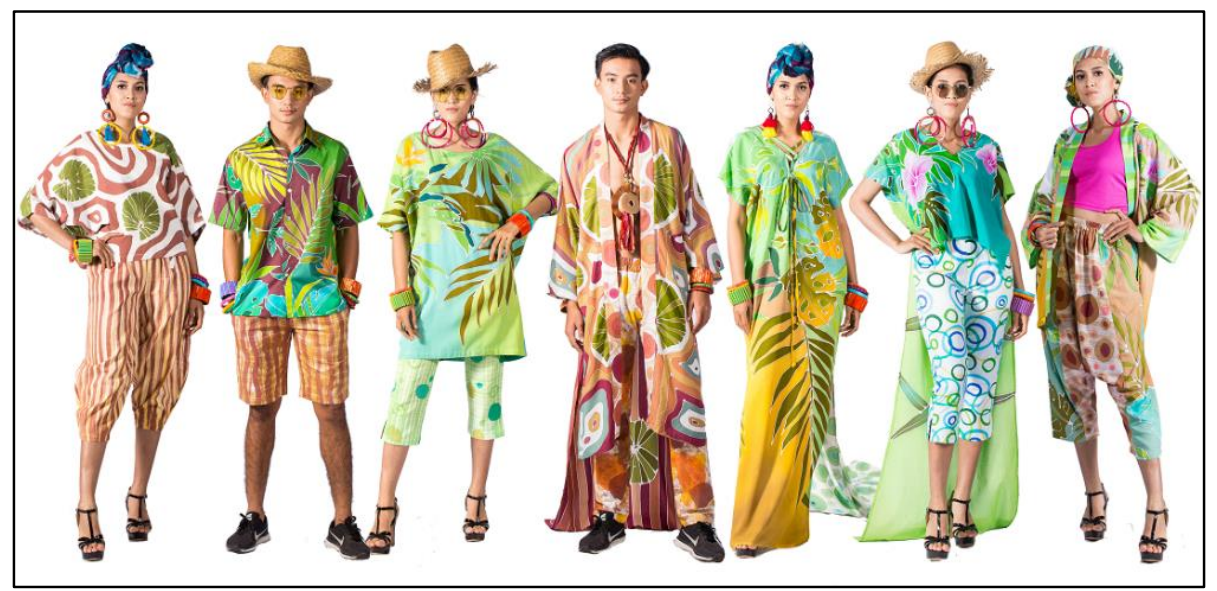

(c)

Figure 4. New batik collections by the (a) Barnrak, (b) Linesen, and (c) Ying batik groups as shown in the lookbook.

The fashion show (see Figure 5) was staged at the largest shopping mall in Nakhon Si Thammarat province as a public showcase of modernized batik products from the community enterprises. Unlike traditional batik products, the clothes were presented and available for purchase as a collection aimed for a younger target group.

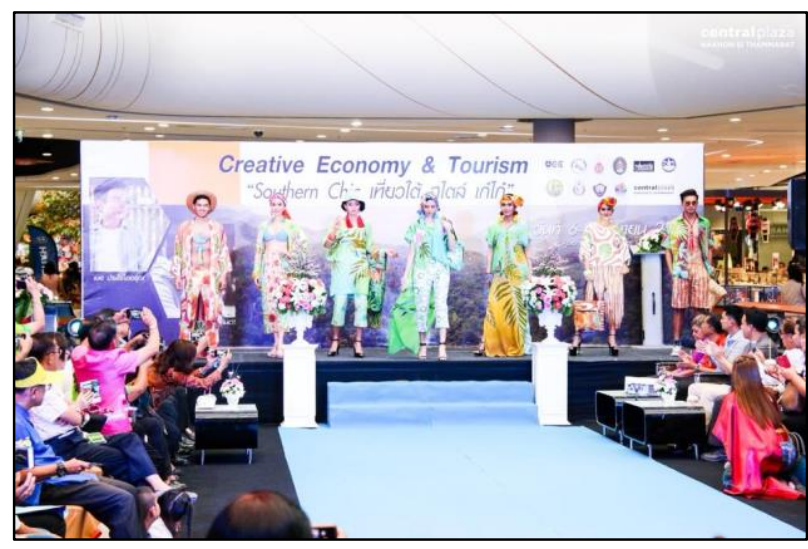

(a)

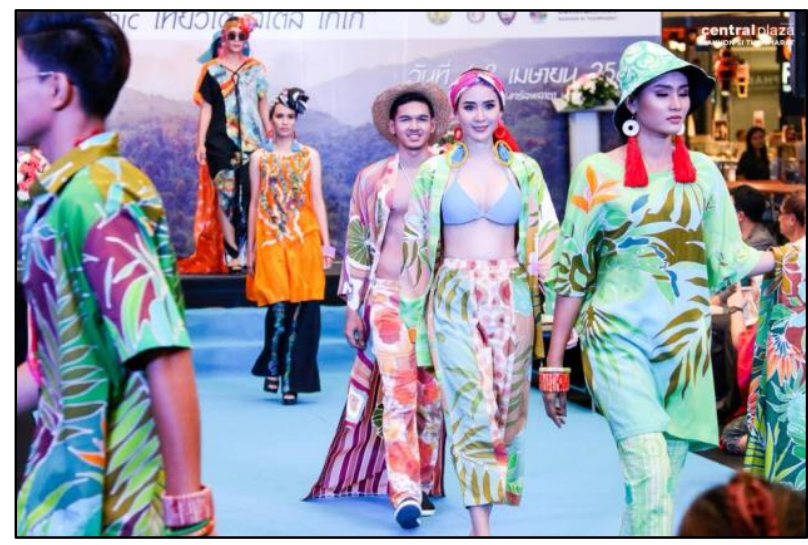

(b)

Figure 5. New batik collections displayed on (a) the stage and (b) the fashion runway in the shopping mall.

Table 2. Comparison of findings from the literature with this work.

\begin{tabular}{|c|c|c|}
\hline Process & Findings from the literature & This work \\
\hline \multirow{5}{*}{$\begin{array}{l}\text { Fabric Design } \\
\text { and Creation }\end{array}$} & $\begin{array}{l}\text { - Some batik artisans are uncomfortable with business } \\
\text { partners and prefer to work within the family [2]. }\end{array}$ & $\begin{array}{l}\text { - The collaboration resulted in three batik collections with the } \\
\text { different characteristics of three community enterprises. }\end{array}$ \\
\hline & $\begin{array}{l}\text { - Computer programs can be used to create and inspect } \\
\text { new batik motifs }[17-20] .\end{array}$ & $\begin{array}{l}\text { - The professional design process was implemented without } \\
\text { computer-aided design. }\end{array}$ \\
\hline & $\begin{array}{l}\text { - The impacts of batik clothes are based on their cultural, } \\
\text { psychological, and aesthetic factors [10]. }\end{array}$ & $\begin{array}{l}\text { - The batik collections have psychological and aesthetic impacts } \\
\text { but may lack cultural meaning. }\end{array}$ \\
\hline & $\begin{array}{l}\text { - Batik is usually made into long clothes and motif } \\
\text { harmonizing is of concern in cutting }[11,24] \text {. }\end{array}$ & $\begin{array}{l}\text {-Motif harmonizing was not an issue in this work, even with the } \\
\text { pants and short-sleeved shirts. }\end{array}$ \\
\hline & $\begin{array}{l}\text { - The batik process could be more environmentally } \\
\text { friendly [27]. }\end{array}$ & $\begin{array}{l}\text { - Organic dye was considered and will be adopted in future } \\
\text { production. }\end{array}$ \\
\hline $\begin{array}{l}\text { Color } \\
\text { Characterization }\end{array}$ & $\begin{array}{l}\text { - Batik colors can be characterized by using a smartphone } \\
\text { under a controlled experiment [21]. }\end{array}$ & $\begin{array}{l}\text { - Untrained people can characterize batik colors by using a } \\
\text { smartphone. }\end{array}$ \\
\hline \multirow{3}{*}{$\begin{array}{l}\text { Collection } \\
\text { Presentation }\end{array}$} & $\begin{array}{l}\text { - Batik fashion shows are regular in Indonesia and } \\
\text { Malaysia }[22,33,34] .\end{array}$ & $\begin{array}{l}\text { - A fashion show introduced batik collections from community } \\
\text { enterprises to the Thai public. }\end{array}$ \\
\hline & $\begin{array}{l}\text { - Batik products can be integrated into community-based } \\
\text { tourism [32]. }\end{array}$ & $\begin{array}{l}\text { - The theme enhanced the reputation of coastal tourism, but } \\
\text { these products have not yet been included in local tourism plans. }\end{array}$ \\
\hline & $\begin{array}{l}\text { - The products' success is strongly influenced by social } \\
\text { media [36]. }\end{array}$ & $\begin{array}{l}\text { - The three community enterprises used Facebook to promote } \\
\text { their products in the country. }\end{array}$ \\
\hline
\end{tabular}




\section{4- Discussion}

The results from this work are compared with those from published works in Table 2 and discussed in detail in this section. The three collections, which are dominated by ancient beads, floras, and marine-themed motifs are consistent with other cases raised by Nurcahyanti et al., that batik artisans found inspiration from local resources, leading to distinctive batik arts from each manufacturing group [22]. It is fitting that batik art thrives on product differentiation [23]. The designs of the batik clothes in collaboration with the three community enterprises were consistent with the design thinking process implemented in batik arts in Lasem town, Indonesia by Basiroen [10]. Basiroen assessed different batik arts from the ideation step based on cultural, psychological, and aesthetic factors [10]. The motifs and designs in these works may have lacked cultural meaning, but they had psychological and aesthetic impacts. The motifs were also advantageous in the cloth cutting stage because they were successfully placed on pants and short-sleeved shirts according to the designated patterns. Motif harmonizing is often an issue in cutting because batik is usually made in the form of long fabrics [11, 24].

Both batik artisans and researchers must be creative and open-minded to encourage the participants to express themselves and develop new creations [25]. A professional design process was introduced to batik artisans. Nevertheless, a computer-aided design was not employed in this work to avoid overloading them with too many new things at once. Computer programs were previously proven successful in batik designs [17-20], but the local batik artisans were not keen to use them. The gradual incorporation of new techniques into traditional craftsmanship is an appropriate way to transform batik into modern fashion without losing its local identity and charm. The batik artisans were unfamiliar with professional processes such as the design brief, but participation in these processes can empower an artisan to develop into an artist-manager [12, 26], a pivotal role in advancing the product and business to successfully become an original brand manufacturer. A batik artist manager should possess knowledge and understanding of creating a unique product and competitive brand. Similar to other products, innovation is a key factor. Another important trend is the development of an environmentally friendly manufacturing process [27]. Future actions in this regard, including the use of natural dyes, are encouraged and will improve the product image. Nawi et al. highlighted the sustainability issues for batik community enterprises in Malaysia [28], and the factors affecting the business of Indonesian Batik Madura were analyzed by Alwiyah et al. [29]. The batik enterprises in Indonesia, Malaysia, and Thailand are primarily rooted in the family businesses of batik artisans [30]. Chen also stated that some batik artisans in China kept businesses within the family to avoid pressure from business managers [2]. This work demonstrates the collaboration between batik artisans from three community enterprises with academic researchers. The advantage of a family business is that creative competence can be driven based on the mutual understanding of the primary purposes and values of the products among family members [31].

Color is among the first attributes that consumers consider when purchasing clothes. However, like other local Thai products, the colors of batik are not measured for the sake of quality control by manufacturers. Batik artisans rely on their experience and universally feel that standard color charts and colorimetric instruments are cumbersome. However, ubiquitous smartphones provide easy on-site analysis for non-experts in the color-matching process. Even a batik community member who is too young to create products can participate in the characterization. The colorimetric application for IOS and Android smartphones is not limited to "Colorimeter"; alternatives like "Catch Color" and "Color Detector" also provide user-friendly interfaces. The fabric color can be measured to ensure uniformity or classify batik products and then refer to a variety of attractive names. Notably, smartphone colorimetry is an essential component of the modernized packages for batik consumers. The process has been extended to practical applications from a controlled experiment [21]. As demonstrated in this study, colors can be quantitatively inspected by the customers themselves.

Product presentation is vital to the public perception of batik, which has mostly been viewed as traditional clothing. Global recognition as a cultural heritage since 2009 has fueled the growth of the batik industry. Like other forms of cultural heritage, batik has been incorporated into community-based tourism [32]. This work has not been directly used as part of the local tourism, but the theme and style of the collections enhanced the reputation of seaside tourism in southern Thailand. Creativity is needed to balance commercial and cultural conservation. The modernized batik with a local identity that differs from those existing in the market has the potential to expand consumer groups. The staged fashion shows enhanced public perception and customer acceptance of batik as fashionable clothing while retaining batik's artistic and community identity. Batik art has been established as one of the creative industries by the Indonesian Creative Economy Agency [33], and batik fashion shows are regularly hosted in Indonesia and Malaysia [22, 34]. In contrast, local batik products are not usually presented as seasonal clothing collections in the modern setting of shopping malls and department stores in Thailand.

After the event, domestic interest in Thai batik significantly increased. The three dress collections with distinctive designs encouraged consumers to purchase more batik products to use on various occasions. Such endeavors generate value-added local products and, hence, more income for SMEs [35]. The processes correspond to the value chain in the fashion industry, from designing and manufacturing clothes to merchandising and marketing products. However, batik community enterprises need to upgrade their clothing production skills to meet consumer demand and actively respond to changes in the ever-changing market. Since the COVID-19 outbreak, an increasing number of customers have turned 
to online shopping. While this situation poses a tough challenge, community-based batik clothes, which have never relied on large physical stores, still have opportunities to prosper in the online marketplace. Social media establishes relationships with customers and greatly influences products' success [36], because of which Facebook fan pages have been exploited by the three batik community enterprises, but they remain within the domestic market.

Finally, the prospects for education will be discussed. In Pekalongan, Indonesia, a network linking schools, museums, governmental institutions, and the batik industry was used to promote batik-related knowledge [37]. An ethnomathematics lesson was suggested based on the batik patterns of Yogyakarta [38]. Batik is inherently related to both science and art, ranging from traditional wisdom to new technology. These rich educational materials have primarily been exploited in mathematics, engineering, folklore, and the arts. The participatory design of batik could be further developed into an engaging course. A lesson on batik colors has the potential to enhance students' knowledge by seamlessly combining the art and science of colors. This aspect of modernized knowledge is vital to conserve the batik culture that still mainly involves the elderly.

\section{5- Conclusions}

Creative processes in art and science were combined to modernize batik clothes manufactured by three local enterprises in southern Thailand. The contributions of this study are summarized as follows:

- The collaboration between the batik artisans and researchers in the design process brought about distinctive patterns inspired by local resources, namely stones, the sea, and flora. New techniques are gradually being incorporated into traditional crafts. Professional design tools, including moodboards, sketches, and lookbooks, are being adopted by local batik artisans. The cutting is planned to position motifs on the clothes, and the neatness of the obtained products is systematically inspected.

- The vivid colors of batik fabrics were simultaneously quantified according to both the RGB and CIE L*a*b* systems as well as chroma and hue values by a smartphone combined with a commercial mobile application named "Colorimeter." Parameters from different color spaces complemented one another in detecting variations in motifs with mixed colors. This characterization process, which is not limited to the laboratory, can be conveniently performed by both manufacturers and customers.

- A fashion show under the theme "Southern Chic" was successfully organized based on these three collections of batik clothes. The presentation in the form of a seasonal collection enhanced the commercial competitiveness and public appeal of the batik clothes, which were previously sold separately or in the form of raw fabrics. The products were also aimed at younger people.

In addition to cultural heritage conservation and commercial benefits, these processes could also be extended to lessons in colors and participatory design.

\section{6- Declarations}

\section{6-1-Author Contributions}

Conceptualization, S.K.; methodology, S.K. and Y.S.; data curation, Y.S.; writing—original draft preparation, S.K. and C.S.; writing — review and editing, Y.S. and C.S.; visualization, S.K.; project administration, S.K. and C.S.; funding acquisition, C.S. All authors have read and agreed to the published version of the manuscript.

\section{6-2-Data Availability Statement}

The data presented in this study are available on request from the corresponding author.

\section{6-3-Funding}

The work is funded by the Ministry of Higher Education, Science and Innovation and also financially supported by the new strategic research project (P2P), Walailak University, Thailand.

\section{6-4-Acknowledgements}

The authors are grateful for the collaboration of Barnrak, Linesen, and Ying batik groups. The contributions of Sakjira Wiangkao, Pantharida Chaijit and the fashion show staff in the design and presentation processes are acknowledged. Smartphone colorimetry was assisted by Krissananan Ekmataruekul.

\section{6-5-Conflicts of Interest}

The authors declare that there is no conflict of interests regarding the publication of this manuscript. In addition, the ethical issues, including plagiarism, informed consent, misconduct, data fabrication and/or falsification, double publication and/or submission, and redundancies have been completely observed by the authors. 


\section{7- References}

[1] Moura, L.R., and H. Kohl. "Maturity assessment in industry 4.0: A comparative analysis of Brazilian and German companies." Emerging Science Journal, 4, no. 5 (2020): 365-375. doi:10.28991/esj-2020-01237.

[2] OIC, 2020. Thailand 4.0. Available online: http://www.oic.go.th/web2017/main_html (accessed on May 2021).

[3] Handayani N. U., D. P. Sari, M. M. Ulkhaq, Y. Widharto, and R. C. A. Fitriani. "A data envelopment analysis approach for assessing the efficiency of sub-sectors of creative industry: A case study of batik enterprises from Semarang, Indonesia.” AIP Conference Proceedings, 2217, no. 1 (2020): 030038. doi:10.1063/5.0000905.

[4] Wanniarachchi, T., and K. Dissanayake. "Improving sustainability and encouraging innovation in traditional craft: The case of the Sri Lankan handloom industry.” Research Journal of Textile and Apparel, 24, no. 2 (2020): 111-130. doi:10.1108/RJTA-092019-0041.

[5] Krisnawati, E., N. Sunarni, L. M. Indrayani, A. N. Sofyan, and T. Nur. "Identity exhibition in batik motifs of Ebeg and Pataruman." Sage Open, 9, no. 2 (2019): 1-7. doi:10.1177/2158244019846686.

[6] Chen, Z., X. Ren, and Z. Zhang. "Cultural heritage as rural economic development: Batik production amongst China's Miao population.” Journal of Rural Studies, 81, (2021): 182-193. doi:10.1016/j.jrurstud.2020.10.024.

[7] Decker, L., R. Trocchianesi, and V. Vacca. "The transcultural identity of batik in the relationship among craft, art and design." Strategic Design Research Journal, 12, no. 2 (2019): 167-176. doi:10.4013/sdrj.2019.122.04.

[8] Shaari, N., and K. A. A. Abd Rahman. "Sustaining batik craft design in Malaysia using indigenous creative knowledge." Pertanika Journal of Social Science \& Humanities, 25, no. S (2017): 81-88.

[9] Sofyan, A. N., E. Krisnawati, and T. Nur. "Pangandaran Batik as a distinctive batik style from the east Priangan region of west Java." Pertanika Journal of Social Science \& Humanities, 28, no. 2 (2020): 1525-1538.

[10] Basiroen, V. J. "Design and commercialization critics of Batik Lasem.” Pertanika Journal of Social Science \& Humanities, 28, no. S1 (2020): 29-42.

[11] Sugiarto, E., A. N. bin Othman, Triyanto, and M. Febriani. "Regional icon motifs: Recent trends in Indonesia's batik fabric development." Vlakna a Textil, 27, no. 1 (2020): 93-98.

[12] Mulyanto, N. S. Prameswari, L. Hartono, F. R. Fuad, and N. L. D. In Diana Sari. "Training models of batik motif design development for designers in micro enterprises." Vlakna a Textil, 27, no. 2 (2020): 74-88.

[13] Widiaty, I., Ana, L. S. Riza, A. G. Abdullah, and S. R. Mubaroq. "Multiplatform application technology-based heutagogy on learning batik: A curriculum development framework.” Indonesian Journal of Science \& Technology, 5, no. 1 (2020): 45-61.

[14] Budiyanto, C. W., I. Widiastuti, and E. S. Wihidayat. "Introducing indigenous culture into online-based courses." Pertanika Journal of Social Science \& Humanities, 25, no. S (2017): 73-84.

[15] Ciurea, C., and E. G. Filip. "The globalization impact on creative industries and cultural heritage: A case study." Creativity Studies, 12, no. 2 (2019): 211-223. doi:10.3846/cs.2019.7753

[16] Widiaty, I., L. S. Riza, A. A. Danuwijaya, R. Hurriyati, and S. R. Mubaroq, "Mobile-based augmented reality for learning 3dimensional spatial batik-based objects.” Journal of Engineering Science and Technology, 10, no. S (2017): 12-22.

[17] Laitupa, D. R. H., T. W. Purboyo, and P. D. Kusuma. "Development of octopus motif for batik pattern on web-based application." ARPN Journal of Engineering and Applied Sciences, 15, no. 12 (2020): 1403-1411.

[18] Tian, G., Q. Yuan, T. Hu, and Y. Shi. “Auto-generation system based on fractal geometry for batik pattern design.” Applied Sciences, 9, no. 11 (2019): 2383. doi:10.3390/app9112383.

[19] Widyantoko, Z., T. P. Widowati, and I. P. Trapsiladi. "Expert role in image classification using CNN for hard to identify object: Distinguishing batik and its imitation.” IAES International Journal of Artificial Intelligence, 10, no. 1 (2021): 93-100. doi:10.11591/ijai.v10.i1.pp93-100.

[20] Nurhaida, I., V. Ayumi, D. Fitrianah, R. A. M. Zen, H. Noprisson, and H. Wei. "Implementation of deep neural networks (DNN) with batch normalization for batik pattern recognition." International Journal of Electrical and Computer Engineering, 10, no. 2 (2020): 2045-2053. doi:10.11591/ijece.v10i2.pp2045-2053

[21] Sirisathitkul, Y., and S. Kaewareelap, “Color analysis of batik fabric by facile smartphone colorimetry.” International Journal of Advanced Science, Engineering and Information Technology, 11, no. 1 (2021): 84-91.

[22] Nurcahyanti, D., Mulyanto, and A. Sachari. "The role of artisans in the batik designs development as a traditional textile in Indonesia." Vlakna a Textil, 28, no. 2 (2021): 45-53.

[23] Nurhayati, T., Mulyanto, and A. Wahida. "Strategic industry of sadewa batik in developing batik images viewed from corporate and product image." Vlakna a Textil, 28, no. 1 (2021): 63-69. 
[24] Mulyanto, N. S. Prameswari, N. Afatara, and L. Hartono. "Pattern design and motif placement of batik sanggit in short-sleeve shirt style." Vlakna a Textil, 26, no. 2 (2019): 37-42.

[25] Chamorro-Koc, M., and G. Caldwell, "Viable futures through design: Community engagement experiences in the creative industries." Creativity Studies, 11, no. 1 (2018): 213-229. doi:10.3846/cs.2018.857.

[26] Szostak, M., and L. Sułkowski, "The challenges in identification of artists-managers: Consequences for creativity." Creativity Studies, 14, no. 1 (2021): 112-124. doi:10.3846/cs.2021.13822.

[27] Fanina, J. J., and F. Suaedi. "Challenges in preserving batik as Indonesia's cultural identity facing global demand of sustainable eco-friendly fabric.” Vlakna a Textil, 27, no. 2 (2020): 37-42.

[28] Nawi, N. C., A. Al Mamun, R. R. R. Daud, and N. A. Md Nasir. "Strategic orientations and absorptive capacity on economic and environmental sustainability: A study among the batik small and medium enterprises in Malaysia." Sustainability, 12, (2020): 8957. doi:10.3390/su12218957.

[29] Alwiyah, E. Steelyana, Sayyida, and I. Tahir. "The survival of batik Madura in digital era: A case study of small medium enterprises (SME) at batik Madura center.” Pertanika Journal of Social Science \& Humanities, 28, no. S1 (2020): 43-57.

[30] Magnadi, R. H., M. S. Perdhana, S. T. Raharjo, and Abdurokhim. "Characteristics of family business succession in batik industry.” Journal of Management Information and Decision Sciences, 24, no. 2 (2021): 1-10.

[31] Bukantaitè, S., and Ž. Sederevičiūtè-Pačiauskienè. "Fashion industry professionals' viewpoints on creativity at work." Creativity Studies, 14, no. 1 (2021): 145-159. doi:10.3846/cs.2021.14277.

[32] Yudana, G., N. S. Surjandari, R. Sugiarti, and I. Aliyah. "Culture-based tourism through optimisation of Lurik and batik industries in Klaten district.” Pertanika Journal of Social Science \& Humanities, 25, no. S (2017): 21-32.

[33] Badan Ekonomi Kreatif. Ekonomi Kreatif Outlook 2019, Jakarta: BEKRAF (2019). Available online: https://www. kemenparekraf.go.id/asset_admin/assets/uploads/media/pdf/media_1589839384_OPUS_Creative_Economy_Outlook_2019_ (Indonesia_Version).pdf. (accessed on May 2021).

[34] Mohamad Akhir, N. H., N. W. Ismail, and C. Utit. "Malaysian batik industry contribution analysis using direct and indirect effects of input-output techniques." International Journal of Business and Society, 19, no. 1 (2018): 181-194.

[35] Kramoliš, J., E. Šviráková, and D. Král. "Design management as crucial creative essence for business success in small and medium-sized enterprises.” Creativity Studies, 13, no. 1 (2020): 87-98. doi:10.3846/cs.2020.9904.

[36] Gashi, R., and H. G. Ahmeti. "Impact of social media on the development of new products, marketing and customer relationship management in Kosovo.” Emerging Science Journal, 5, no. 2 (2021): 125-138. doi.org/10.28991/esj-2021-01263

[37] Wang, C. Y. "Building a network for preserving intangible cultural heritage through education: A study of Indonesian batik." International Journal of Art and Design Education, 38, no. 2 (2019): 398-415. doi:10.1111/jade.12200.

[38] Prahmana, R. C. I., and U. D'Ambrosio. "Learning geometry and values from patterns: ethnomathematics on the batik patterns of Yogyakarta, Indonesia." Journal on Mathematics Education, 11, no. 3 (2020): 439-456. doi:10.22342/jme.11.3.12949.439456. 